\title{
Locate fugitive methane emission from compressor station of natural gas transmission and distribution system for reducing environmental risk
}

\begin{abstract}
Fugitive emissions are the source of methane emission to the atmosphere. Though fugitive methane emission occurs throughout the entire natural gas pipeline system, compressor stations (CSs) are the largest source of methane emission of natural gas transmission and distribution system. Literature revealed that Methane gas emissions have a richer warming effect on climate. For reducing methane release to atmosphere from gas transmission and distribution system, locating fugitive emission is vital. The aim of this paper is to develop fugitive emission model to locate fugitive leak. Then the developed model is utilized to locate fugitive leak from the CS Akchalok, Uzbekistan. Finally, economic and environmental impacts for such fugitive emissions are also critically evaluated. In this study, the conservation of mass and momentum equations for the steady state subsonic flow of gas through a constant diameter, rigid pipe were utilized to develop fugitive natural gas release model. The recorded gas release from CS Akchalok data were used to locate potential gas release. The results show that Compressor 5 was the major gas releasing part of CS of Akchalok, Uzbekistan. The $K_{\text {leak }}$ value of this station was approximately $90.81 \times 10$ ${ }^{9} \mathrm{~m}^{2}$ that was approximately 67.27 times greater than the Compressor $7\left(1.35 \times 10^{-9} \mathrm{~m}^{2}\right)$. It is vital to reduce emission from Compressor 5 on priority basis to save the environment. CS Akchalok can save USD 1.28 million yearly by stopping gas release to the atmosphere parallel to mitigate climate change.
\end{abstract}

Keywords: fugitive emission, compressor station, methane release, gas leakage, climate mitigation
Volume 2 Issue 4 - 2017

\author{
PC Mandal,,'2 M Gapparova ${ }^{3}$ \\ 'Department of Chemical Engineering, Universiti Teknologi \\ PETRONAS, Malaysia \\ ${ }^{2}$ Titas Gas Transmission and Distribution Co. Ltd, Bangladesh \\ ${ }^{3}$ Department of Petroleum Engineering, Universiti Teknologi \\ PETRONAS, Malaysia
}

\begin{abstract}
Correspondence: PC Mandal, Department of Chemical Engineering, Universiti Teknologi PETRONAS, Malaysia,
\end{abstract} Email pradip.mandal@utp.edu.my

Received: April 17, 2017| Published: May 04, 2017

\section{Introduction}

The world's demand of natural gas, a fossil fuel, is increasing day by day. Kulkarni in $2013^{1}$ have disclosed that its demand is increasing $1.5 \%$ annually and this trend will be continued up to 2030 . It is vital energy source of the world due to its low emission, higher efficiency, affordability, abundant availability and easy usage. ${ }^{1}$ Natural gas contain approximately $90 \%$ methane, a second most uncontrolled man-made greenhouse gas next to carbon dioxide $\left(\mathrm{CO}_{2}\right){ }^{2,3}$ Although methane has a shorter life-time than $\mathrm{CO}_{2}$, lasting only 12 years in the atmosphere, its heat trapping capability is 25 times greater than $\mathrm{CO}_{2}$ on a 100 -years' time horizon. Therefore, methane is an important promoter of climate change after $\mathrm{CO}_{2}$. For this reason, reduction of methane releasing in the atmosphere is now a pressing issue to mitigate climate change. Natural gas is not only the source of methane emission to the atmosphere; there are about ten sources of methane emissions. Gas industry is the second place after enteric fermentation. ${ }^{4}$ Methane released in oil and gas facilities can cause explosions creating direct risk for working personnel. The main and preferred way of natural gas transportation is usually through natural gas pipelines. ${ }^{5}$ Generally, pipelines are connected with compressors and many above ground facilities to control and measure pressure, temperature and flow rate for uninterrupted gas supply. Natural gas releases to the atmosphere through fugitive, vented and combusted emissions. Fugitive emissions are unintentional leaks steadily from pipeline and system components, such as flanges, valves, equipment leaks, sampling connections, and open-ended lines and much later. ${ }^{6,7}$ Methane release to the atmosphere through fugitive emission can be reduced by stopping emissions after locating potential fugitive gas releasing points.

The gas industry is divided into four segments: production, processing, transmission/storage and distribution. Figure 1 presents schematic location of each industry segment and equipment in each system that is performing as potential source of the minor leakage. Gas distribution system is the third, after gathering and transmission pipeline systems, which is responsible for natural gas distribution to households and industrial customers through large distribution lines mains and service lines. ${ }^{8}$ It is considered as a final step of whole gas system in delivering natural gas to customers. The main components of the system are City Gate Station (CGS), Town Bordering Station (TBS), District Regulating Station (DRS), Regulating and Metering Station (RMS). ${ }^{9,10}$

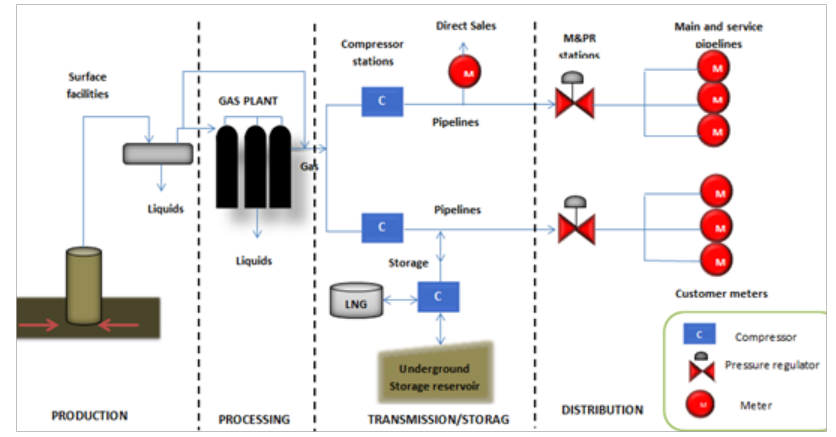

Figure I Gas industry flow chart. ${ }^{8}$ 
Uzbekistan, a doubly landlocked country in central Asia, has a highly distributed gas fields and main gas pipelines network. There are nine long distance gas pipelines totaling $12,660 \mathrm{~km}$ with access to the Commonwealth of Independent States' (CIS) integrated gas system. The gas transporting capacity of the pipelines is more than 20 billion cubic meters to transport gas to Central Asia, Russia and Ukraine. ${ }^{11}$ The main gas pipelines are with diameters of 1000, 800 and $700 \mathrm{~mm}$ having operational pressure of $7.5 \mathrm{MPa}$. Figure 2 demonstrates the Natural Gas system of Uzbekistan, which is in the list of top three methane emitters from oil and natural gas industry in $2010 .{ }^{4}$ Flow chart shows the main stages and components of a system and pressure change at each stage.

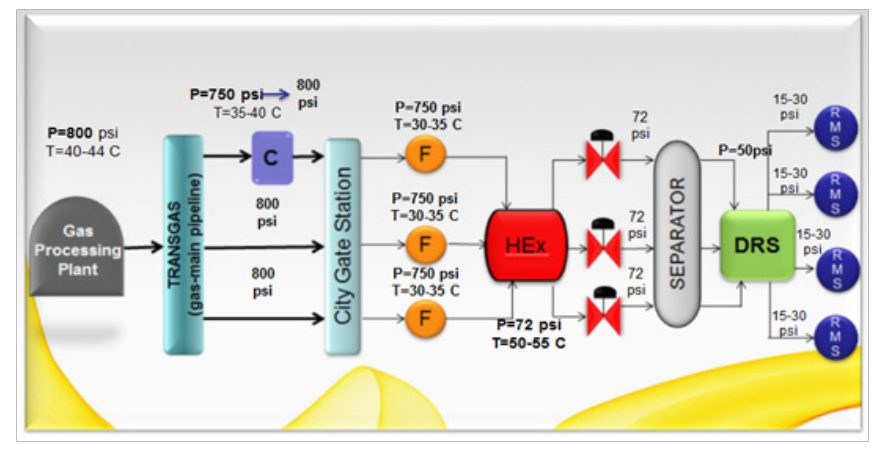

Figure 2 Natural Gas pipeline system flow chart of Uzbekistan.

Uzbekistan pipeline network is operated by JSC Uz TransGas (UTG), a subsidiary of the National Holding Company, Uzneftegas. The company provides uninterrupted supply of natural gas to 4,519,806 houses and apartments, 80,912 wholesale customers. ${ }^{12}$ The pipeline complex operated by UTG includes 25 compressor stations. The Akchalok compressor station (CS) used in this study is one of them. This station is owned and operated by Urgenchtransgas, a subsidiary of $\mathrm{UTG}^{13}$. It is located in the Autonomous Republic of Karakalpakstan, in Kungrad district. It is built in 1976 and commissioned during 19761984. The main function of this station is to pressurize natural gas received from Turkmenistan through truck gas pipeline Central Asia to Center, namely Russia (CAC-II) and CAC-IV with total served pipeline length of $568 \mathrm{~km} .{ }^{11}$

A mathematical model of accidental gas release from long transmission pipelines are represented by using of computational fluid mechanics. Literature revealed that the existing hole-model is suitable for predicting gas release through a small punctured hole while the other existing pipe model is suitable to predict the gas release through a complete break in the pipe. ${ }^{14,15}$ Yuhu et al. ${ }^{15}$ proposed a new holemodel that lies between the above two situations. Reddy et al ${ }^{16}$ used a computationally efficient transfer function based state estimation model for dynamic flows in a hypothesis testing framework for developing an approach for leak detection and identification in gas pipeline networks. Moloudi \& Esfahani ${ }^{17}$ proposed a unique mass discharge function by surveying dimensionless gas release rate parameters of pipeline rupture. In the same year, Lu et al. ${ }^{18}$ investigated the discharge rate and mass release over time by developing different hole model based on hole diameters. There is no model for representing fugitive emission through above ground facilities of gas transmission and distribution systems in open literature.

The objective of current paper is to develop mathematical model of fugitive natural gas leak constant $\left(K_{\text {leak }}\right)$ and apply developed model in calculation of $K_{\text {leak }}$ of CS Akchalok, Uzbekistan by locating the emissions from above ground facility of compressor station. In addition, economic and environmental impacts for such fugitive emissions are also evaluated.

\section{Materials and methods}

\section{Fugitive gas released model}

Hole of natural gas pipeline is a rupture of pipeline where the area of hole is a miserable quantity and gas release from this hole is mathematically expressed by hole model. Moloudi \& Esfahani ${ }^{17}$ have expressed gas release model by hole model when the relative diameter (hole size divided by pipe diameter) is less than $15 \%$ and rupture model is used elsewhere. Lu et al. ${ }^{18}$ investigated gas release using the small hole model (hole diameter is less than or equal to $20 \mathrm{~mm}$ ), full bore model (hole diameter is greater than or equal to pipe diameter) and large hole model (hole diameter is greater than $20 \mathrm{~mm}$ but less than pipe diameter). The state of gas in the pipeline is constant and consistent, and flow in the hole is isentropic in the small hole model. In the full bore model, the flow in the pipe is adiabatic, and there is no isentropic expansion from the middle of pipe to the gas releasing point. Large bore model takes into account both the isentropic flow at the hole as the small hole model and the adiabatic flow in the pipe as the full bore model. In 2015, Li et al. ${ }^{19}$ discovered that hole model can predict flow accurately for small leakage holes. Thus these models can predict accidental gas release that is mainly a function of pressure, friction term and hole size. Gas release rate of hole model depends only on relative hole diameter not on pressure and friction term. In the rupture model, gas release rate is a function of friction term and diameter. There is no model for fugitive gas release from pressurized gas pipeline. Small hole model can be used to predict fugitive gas release.

The mathematical fugitive gas release model can be developed combining four main formulas stated below:

$$
\begin{aligned}
& \text { Equation of State: } \frac{P}{\rho}=\frac{Z R T}{M} \\
& \text { Continuity equation: } \rho_{1} A_{1} v_{1}=\rho_{2} A_{2} v_{2} \\
& \text { Poisson equation: } \frac{P_{1}}{\rho_{1}^{k}}=\frac{P_{2}}{\rho_{2}^{k}}
\end{aligned}
$$

Energy and momentum balance equation:

$$
\frac{k+1}{k} \ln \left(\frac{P_{1} T_{2}}{P_{2} T_{1}}\right)+\frac{M}{R G^{2}}\left(\frac{P_{2}^{2}}{T_{2}}-\frac{P_{1}^{2}}{T_{1}}\right)+\frac{4 f L_{e}}{D}=0
$$

For flowing gases with small pressure changes and low velocities the kinetic energy changes are negligible and densities are constant. Energy contained within the gas is converted into the kinetic energy as the gas escapes through the leak. The density, pressure and temperature change as the gas exits through the hole. For free expansion releases assumption of isentropic behaviour is usually valid. Figure 3 shows schematic fugitive gas release diagram of pressure regulation valve of a pipeline indicating a hole located at distance, L. Point 1 indicates the initial point at the starting of length, L; point 2 is located at inside the pipeline on a level of the hole. 
The fugitive gas emission model is derived for steady state subsonic flow under assumptions of the flow is one-dimensional, adiabatic in the pipeline; pipeline pressure is not affected by gas release; pipeline has no inclination and gas expansion is isentropic. The pipeline is considered as a tank when the diameter of hole is small. Gas release rate is obtained by substituting Eq. (1), Eq. (2) and Eq. (3) into Eq. (4) and can be expressed as

$$
Q_{m}=C_{d} A_{d} P_{2} \sqrt{\frac{2 M}{Z R T_{2}} \frac{k}{k-1}\left[\left(\frac{P_{a}}{P_{2}}\right)^{\frac{2}{k}}-\left(\frac{P_{a}}{P_{2}}\right)^{\frac{k-1}{k}}\right]}
$$

This equation demonstrates hole model. The empirical discharge coefficient, $C_{d}$, have a fixed value either 0.61 (for subsonic flow of Reynolds number greater than 30,000) or 1 (for other situations). The gas leaking area, $A_{d}$, is very small and not a measurable quantity. Thus, the product of $C_{d}$ and $A_{d}$ can be considered as a constant value for a particular fugitive gas release and express as $K_{\text {Leak }}$. Inserting $K_{\text {Leak }}=$ $C_{d} A_{d}$ in Eq. (5), the expression of gas release rate can be written as

$$
C P R=\frac{P_{a}}{P_{2 c r}}=\left(\frac{2}{k+1}\right)^{\frac{k}{k-1}}
$$

Thus the respective leak constant expression for subsonic flow and sonic flow can be expressed a

$$
\begin{aligned}
& K_{\text {Leak }}=\frac{Q_{m}}{P_{2} \sqrt{\frac{2 M}{Z R T_{2}} \frac{k}{k-1}\left[\left(\frac{P_{a}}{P_{2}}\right)^{\frac{2}{k}}-\left(\frac{P_{a}}{P_{2}}\right)^{\frac{k-1}{k}}\right]}} \\
& K_{\text {Leak }}=\frac{Q_{m}}{P_{2} \sqrt{\frac{M}{Z R T_{2}} k\left(\frac{2}{k+1}\right)^{\frac{k+1}{k-1}}}}
\end{aligned}
$$

Table I $K_{\text {leak }}$ values of compressors located at CS Akchalok

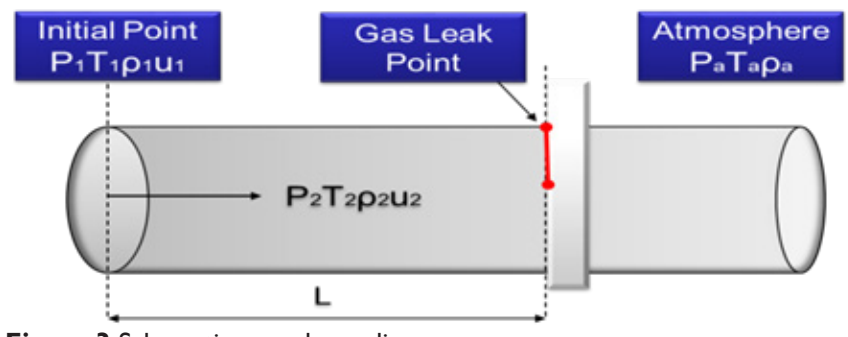

Figure 3 Schematic gas release diagram.

\section{Field data collection and released gas quantification}

The methane concentration in natural gas passing through CS Akchalok was measured to be $97 \% .^{13}$ The measurement study found 40 leaks at different components of compressors present at Akchalok. The gas leak data were collected from leak sources of CS Akchalok such as unit valves, blow-down valves of compressor station as they were the vital gas leaking points. The gas leak rate and corresponding leak constant were evaluated. For methane $(k=1.3)$ the $\mathrm{CPR}\left(P_{a} / P_{2 c r}\right)$ is 0.55 . If the value of $P_{2}$ is greater than $P_{2 c r}$, the gas release is known as sonic release where the Mach number $(M a=v / c)$ at the gas exit point is unity. The values of $K_{\text {Leak }}$ were determined using Eq. (7) for sub-sonic flow and Eq. (8) for sonic flow.-

\section{Results and discussion}

\section{Fugitive emission from CS akchalok}

CS Akchalok was constructed and commissioned from 1978 to 1984. Nineteen compressors are installed at CS Akchalok upto-date. ${ }^{13}$ All compressors are centrifugal compressors driven by gas combustion turbines. The gas leaked data were collected from discreetly chosen 8 compressors based on historical data. The gas leaked data; estimated emission data and $K_{\text {leak }}$ value of the respective compressors located at CS Akchalok are tabulated in Table 1. The results depict that compressor 5 has the highest $K_{\text {leak }}$ value $\left(90.81 \times 10^{-9}\right.$ $\left.\mathrm{m}^{2}\right)$ and compressor 7 has the lowest $K_{\text {leak }}$ value $\left(1.35 \times 10^{-9} \mathrm{~m}^{2}\right)$. Thus the compressor station 5 is considered as a high risk prone compressor

\begin{tabular}{|c|c|c|c|c|c|c|}
\hline $\begin{array}{l}\text { Compressor } \\
\text { number }\end{array}$ & $\begin{array}{l}\text { Year of } \\
\text { commission }\end{array}$ & $\begin{array}{l}\text { Suction/ Discharge } \\
\text { pressure } \\
\text { (Bar/Bar) }\end{array}$ & $\begin{array}{l}\text { Gas leak rate } \\
\left(\mathrm{M}^{3} / \mathrm{Hr}\right)\end{array}$ & $\begin{array}{l}\text { Leak } \\
\text { volume } \\
\text { (Mmcmy) }\end{array}$ & $\begin{array}{l}K_{\text {leak }}=C_{d} a_{d} \\
(\times 10-9)(M 2)\end{array}$ & $\begin{array}{l}\text { Estimated } \\
\text { emission } \\
\left(\mathrm{Mtco}_{2} \mathrm{e} / \mathrm{Yr}\right)\end{array}$ \\
\hline 5 & $|980-198|$ & $62.2 / 68.5$ & 1,145 & 9.89 & 90.81 & 144.45 \\
\hline 13 & 1984 & $25.2 / 35.4$ & 93.25 & 0.81 & 7.4 & 11.76 \\
\hline 4 & $|980-198|$ & $62.2 / 68.5$ & 78.43 & 0.68 & 6.22 & 9.89 \\
\hline 14 & 1984 & $25.2 / 35.4$ & 58.78 & 0.51 & 4.66 & 7.42 \\
\hline 11 & 1984 & $25.2 / 35.4$ & 54.31 & 0.47 & 4.31 & 6.85 \\
\hline 6 & $|980-198|$ & $62.2 / 68.5$ & 47.71 & 0.41 & 3.78 & 6.02 \\
\hline 9 & $1980-198 \mid$ & $62.2 / 68.5$ & 22.65 & 0.2 & 1.8 & 2.86 \\
\hline 7 & $|980-198|$ & $62.2 / 68.5$ & 16.97 & 0.15 & 1.35 & 2.14 \\
\hline \multicolumn{3}{|c|}{ Total (8 Compressors): } & $\mathrm{I}, 5 \mathrm{I7}$ & 13.11 & & 191.39 \\
\hline \multicolumn{3}{|c|}{ Total (19 Compressors): } & 2101.83 & 18.16 & & 265.16 \\
\hline
\end{tabular}
of the CS Akchalok. This compressor should be decommissioned due to the high level of risk for fire and explosion as well as environmental burden.

The leak sources are all from unit and blow-down valves. 
This study showed that total volume of leaked gas was 18.16 MMCM per year. CS Akchalok was transported average 51,860 MMCM natural gas during 2003-2007. Approximately $0.04 \%$ of the transported gas were releasing from the CS Akchalok annually. The percentage of gas leak from gas distribution system of Titas Gas of Bangladesh, different distribution companies of USA and Moldova were 2.10, 2.62 and 5.00 respectively. ${ }^{3}$ So, the gas leaked rate of CS Akchalok is less than other distribution companies of the world as this study was considered one compressor station out of 25 compressor stations.

\section{Environmental and economic effects}

Based on available data, around 3.6 trillion cubic feet (TCF) of natural gas escaped into the atmosphere in 2012 from global oil and gas operations. ${ }^{20}$ In addition, the list of countries with respect to methane emission, first three leading countries are the Russia, the USA and the Uzbekistan. Table 2 revealed that there is a significant different between countries in terms length of pipelines system, number of compressor stations, territorial area of each country and calculated value of methane emission per square kilometres and $\mathrm{km}$ pipeline. The territorial area of Uzbekistan is 38 times smaller than Russian area and 22 times smaller than US area. But the amount of methane emissions per square kilometres or per square kilometres pipeline of Uzbekistan is significantly higher than both the countries. It is also seen that CS Akchalok of Uzbekistan is emitting methane to the atmosphere $0.27 \%$ of country's yearly emission. Moreover, one $\mathrm{km}$ pipeline of CS Akchalok is emitting approximately 4.70 $\mathrm{MMTCO}_{2} \mathrm{e}$ of methane to the atmosphere annually.

Table 2 Methane emission from oil and gas industry of the top three countries of the world

\begin{tabular}{|c|c|c|c|c|c|c|}
\hline Country & $\begin{array}{l}\text { Length of } \\
\text { pipeline } \\
\text { (Thousand }\end{array}$ & $\begin{array}{l}\text { No of compressor } \\
\text { station } \\
\text { m) }\end{array}$ & $\begin{array}{l}\text { Area of the } \\
\text { country } \\
\left(\mathrm{MM} \mathrm{Km}^{2}\right)\end{array}$ & $\begin{array}{l}\text { Yearly methane } \\
\text { emission } \\
\left(\mathrm{MMTCO}_{2} \mathrm{e}\right)\end{array}$ & $\begin{array}{l}\text { Yearly methane } \\
\text { emission per } \mathrm{Km}^{2} \\
\left(\times \mid 0^{-5}\right)\end{array}$ & $\begin{array}{l}\text { Yearly methane } \\
\text { emission per } \mathrm{Km} \\
\left(\times 10^{-4}\right)\end{array}$ \\
\hline Russia & 162 & 4,268 & 17.098 & 387 & 2.26 & 23.89 \\
\hline USA & 485 & 7,864 & 9.857 & 192 & 1.95 & 3.96 \\
\hline Uzbekistan & 12.66 & 25 & 0.449 & 97 & 21.6 & 76.62 \\
\hline $\begin{array}{l}\text { CS Akchalok, } \\
\text { Uzbekistan }\end{array}$ & 0.568 & 1 & 0.449 & 0.265 & 0.06 & 4.7 \\
\hline
\end{tabular}

The gas tariff in Uzbekistan is charging local consumers, including domestic industries, 151,740 sums (USD 70.70 at the official exchange rate) per thousand cubic meters of natural gas. ${ }^{21}$ The total volume of gas emitted as fugitive from CS Akchalok was close to 18.16 MMCM per year whose price is approximately USD 1.28 million annually. Thus the owner of CS Akchalok can save approximately USD 1.28 million annually by stopping emissions through minor source of emission from Akchalok compressor station.

\section{Conclusion}

Gas release from pipelines can be controlled to the acceptable range as it can cause major human injuries, financial loss and environmental pollution. $K_{\text {leak }}$ value of compressor 5 of CS Akchalok is $90.81 \times 10^{-9} \mathrm{~m}^{2}$ that is 67.27 times higher than the compressor 7. This result indicates that compressor 5 is environmentally inefficient and need to be decommissioned. CS Akchalok is releasing $0.04 \%$ of its transported gas to the atmosphere as a fugitive emission. In addition, it is emitting approximately 4.70 $\mathrm{MMTCO}_{2}$ e methane from each $\mathrm{km}$ of pipelines. These results indicate that CS Akchalok is not environmentally benign compressor station of the country. The company can save USD 1.28 million annually by stopping fugitive emission.

\section{Acknowledgments}

This work was supported by the Department of Petroleum Engineering, Universiti Teknologi PETRONAS.

\section{Nomenclature}

$A_{d} \quad$ Area of gas release point $\left(\mathrm{m}^{2}\right)$

$A$ Area of cross-section of pipeline $\left(\mathrm{m}^{2}\right)$

$C_{d}$ Empirical discharge coefficient, for subsonic of Reynolds number greater than $30,000, C_{d}=0.61$, for other situations $C_{d}=1$ $c \quad$ Speed of sound $\left(\mathrm{m} \mathrm{s}^{-1}\right)$

$D$ Pipeline diameter (m)

$f \quad$ Friction factor

$G \quad$ Mass flux $\left(\mathrm{kg} \mathrm{m}^{-2} \mathrm{~s}^{-1}\right)$

$K_{\text {Leak }} \quad$ Leak constant $\left(\mathrm{m}^{2}\right)$

$L_{e} \quad$ Equivalent length of pipeline $(\mathrm{km})$

$M$ Molecular weight $\left(\mathrm{kg} \mathrm{kmol}^{-1}\right)$

$P$ Pressure $(\mathrm{Pa})$

$Q \quad$ Gas release rate $\left(\mathrm{kg} \mathrm{s}^{-1}\right)$

$R \quad$ Constant of gas $\left(\mathrm{Pa} \mathrm{m}^{3} \mathrm{~mol}^{-1} \mathrm{~K}^{-1}\right)$

$T$ Temperature (K)

$u \quad$ Speed of gas $\left(\mathrm{m} \mathrm{s}^{-1}\right)$

Z Compressibility factor

$k \quad$ The ratio of specific heats

$\rho \quad$ Density of gas $\left(\mathrm{kg} \mathrm{m}^{-3}\right)$

\section{Subscripts}
1 Initial point
2 Point inside the pipeline
a Point in the atmosphere
cr Critical

\section{Acknowledgements}

None 


\section{Conflict of interest}

The author declares no conflict of interest.

\section{References}

1. Kulkarni A. The global gas industry: a cleaner energy source needs a smart workforce. Soft Skills. 2013;9(2):25-26.

2. EDF. Economic analysis of methane emission reduction opportunities in the U.S. onshore oil and natural gas industries, Environmental Defense Fund. 2014.

3. Mandal PC, Chowdhury S, Morshed SM. Fugitive methane emissions from the natural gas distribution network of Titas Gas and the environmental risks. UK: WIT Press; 2015. 206:137-148.

4. GMI. Global methane emissions and mitigation opportunities, Global Methane Initiative. 2010.

5. Mandal PC. Gas Leak Detection in Pipelines \& Repairing System of Titas Gas. Journal of Applied Engineering. 2014;2(2):23-34.

6. Jelinek KA, Rooney TC, Webb MG. Fugitive emissions from an offshore oil and gas production platform. SPE International. 1993;p. 119-124.

7. Nwaoha C. Controlling Fugitive Emissions in Nigeria's Oil and Gas Industry:Proper Sealing Device Selection a Panacea. SPE International. 2010;p.1-9.

8. Campbell L, Campbell M, Cowgill M, et al. Methane Emissions from the Natural Gas Industry. NASA-no. 19980003766. 1997.

9. ORUI. Energy \& Safety: Natural Gas: Gas Pipeline System. Orange and Rockland Utilities Inc. (ORUI). 2015.

10. Folga SM. Natural Gas Pipeline Technology Overview. Decision and Information Sciences. United States, 2007.
11. UNDP. Design and rollout of a system for monitoring of gas leakages Uzbekistan, United Nations Development Programme. USA, 2008.

12. UTZ. Main factors. Uztransgaz, 2011.

13. UNFCC. Reduced gas leakage at compressor stations, United Nations Framework Convention on Climate Change, CDM, JSC UzTransGas. Uzbekistan, 2011.

14. Yuhua D, Huilin G, Jing'en Z, et al. Evaluation of gas release rate through holes in pipelines. J Loss Prevent Proc. 2002;15(6):423-428.

15. Yuhu D, Huilin G, Jingen Z, et al. Mathematical Modeling of Gas Release through Holes in Pipelines. Chem Eng J. 2003;92:237-241.

16. Reddy HP, Narasimhan S, Bhallamudi SM, et al. Leak Detection in Gas Pipeline Networks Using an Efficient State Estimator. Part-I:Theory and simulations. Comput Chem Eng. 2011;35:651-661.

17. Moloudi R, Esfahani JA. Modeling of gas release following pipeline rupture:Proposing non-dimensional correlation. J Loss Prevent Proc. 2014;32:207-217.

18. Lu L, Zhang X, Yan Y, et al. Theoretical Analysis of Natural-Gas Leakage in Urban Medium-pressure Pipelines. J Environ Hum. 2014;1(2):71-86.

19. Li K, Zhou X, Tu R, et al. Experimental investigation of $\mathrm{CO}_{2}$ accidental release from a pressurised pipeline. Energy Procedia. 2015;75:22212226.

20. Larsen K, Delgado M, Marsters P. Untapped Potential Reducing Global Methane Emissions from Oil and Natural Gas Systems, Environmental Defense Fund. 2015;p.1-27.

21. Sadykov M. Uzbekistan ups domestic gas tariffs again, but still fraction of export price, Choihona. Uzbekistan, 2013. 